\title{
I Do Not Even Say “It" - a Mixed Methods Study on Breast Cancer Awareness of Omani Women
}

\author{
Esra Alkhasawneh $^{1 *}$, Saad T Siddiqui ${ }^{1}$, Michael Leocadio ${ }^{1}$, Vidya Seshan $^{1}$, Yahya \\ Al-Farsi' ${ }^{2}$ Mansour S Al-Moundhri'
}

\begin{abstract}
Background: The incidence of breast cancer is rising in Oman, and the disease is diagnosed at late stages, when treatment success is limited. Omani women might benefit from better awareness, so that breast cancer can be detected early and treated. This study was conducted to assess Omani women's levels of breast cancer awareness and early detection practice, and explore factors which might influence these levels. Materials and Methods: A mixed methods study was conducted in 2014, including a quantitative survey of 1,372 and a qualitative assessment of 19 Omani women, aged $\geq 20$ years from five Omani governorates using convenient sampling. Demographic information and scores for awareness levels were used in a multivariate regression model to investigate factors associated with awareness. Thematic analysis and interpretive description were used to analyse the qualitative data. Results: The overall means for early detection and general awareness scores were 0.58 (SD 0.24$)$ and 0.46 (SD 0.21), respectively. General awareness was significantly associated with age, education, income and familiarity with cancer patients $(\mathbf{p}<0.05)$, while early detection was significantly associated with age, marital status and education. A majority of women (59.5\%) agreed with a belief in 'evil eye' or envy as a risk factor for breast cancer. Women discussed various factors which may empower or inhibit awareness, including the cultural-religion-fatalistic system, personal-familial-environmental system, and healthcare-political-social system. Conclusions: The overall low scores for awareness and early detection, and the survey of local beliefs highlight a severe necessity for a contextually-tailored breast cancer awareness intervention programme in Oman.
\end{abstract}

Keywords: Awareness - beliefs - breast cancer - health promotion - muslims - oman

Asian Pac J Cancer Prev, 17 (4), 2247-2254

\section{Introduction}

Breast cancer is the most common cause for women's cancer-related morbidity and mortality worldwide (WHO, 2014). Lesser developed countries now bear a greater burden of the disease, where cases are usually diagnosed in late stages (Kumar et al., 2011; WHO, 2014), and where $62 \%$ of all breast cancer-related deaths occur (IARC, 2012). Likewise, breast cancer is a growing burden on women's healthcare in the Sultanate of Oman, where women are diagnosed with the disease at a younger age and a more advanced stage than in developed countries (Al-Moundhri et al., 2004; Kumar et al., 2011).

In Arab countries such as Oman, breast cancer remains poorly understood in terms of health promotion and prevention (Al-Azri et al., 2014). This is most commonly due to fear of cancer, shyness, poor health education and difficult access to health care facilities (Kumar et al., 2011; Al-Azri et al., 2014). slamic teachings value health promotion and disease prevention, breast screening tests are not routinely practiced (Donnelly et al., 2013). Arab women are also apprehensive about the process of breast cancer screening, since they require consideration from healthcare professionals about their beliefs, values, and customs as Muslims (Underwood et al., 1999; Donnelly et al., 2013).

There is consistent evidence that breast cancer awareness contributes to earlier identification and reporting of symptoms (Anderson and Jakesz, 2008; Kalager et al., 2010; Welch, 2010). Factors such as health beliefs and attitudes towards breast cancer, general breast cancer knowledge and screening knowledge, socioeconomic status and level of education have also been linked with screening use (Raza et al., 2012; Donnelly and Hwang, 2015).

The current study is essential given the fact that breast cancer is the most common cancer among women in Oman (Renganathan et al., 2014). This study was funded by His Majesty the Sultan's Strategic Research Fund, with the aim of obtaining baseline information on the current status of breast cancer awareness among women in seven Omani governorates, with an ultimate goal of 
defining strategies that may be implemented to increase awareness of breast cancer and increase screening rates. More importantly, ensuring the dispersal of correct information in Omani society may help dispel locally prevalent myths surrounding breast cancer and facilitate treatment in patients diagnosed with breast cancer. To facilitate this aim, we used a mixed methods study design to [a] determine the level of awareness of Omani women about breast cancer in general and its early detection practices, and [b] explore significant factors that affected or may affect their awareness related to this phenomenon.

\section{Materials and Methods}

We conducted a mixed methods study to quantitatively estimate the level of awareness of Omani women (general and early detection practices) and investigate any influence that demographic factors may have on awareness. Additionally, we qualitatively investigated factors that affected or may affect Omani women's awareness of breast cancer. We used this study design for triangulation, offset, completeness, context, illustration, diversity of views, and enhancement to build on the initial quantitative findings (Creswell and Clark, 2011).

Using a sequential mixed methods design, we first employed a quantitative cross-sectional study in the Batinah, Dakhiliyah, Dhahirah, Dhofar, Musandam, Muscat and Sharqiyah governorates of Oman. We recruited 1372 Omani women aged 20 years or older through convenience sampling from strategic locations in the different governorates, while maintaining the proportions according to the population density of each governorate. Women who had been diagnosed with breast cancer were excluded from the survey. After obtaining ethical approval from the university ethics committee, data were collected using a translated, adapted and subsequently validated version of the Breast Cancer Awareness Measure (CAM) Toolkit (Version 2), as developed in 2009 by Cancer Research UK, King's College London and University College London and validated with the support of Breast Cancer Care and Breakthrough Breast Cancer (Cancer Research UK, 2008; Linsell et al., 2010).

The survey instrument included questions to establish participants' demographics - including age, marital status, level of education, employment status, income level, and whether the participant knows a relative or friend with breast cancer - breast self-exam (BSE) behaviour, confidence and skills; seeking of medical help; awareness of early detection signs; awareness of risk factors; and awareness of a National Cancer Early Detection Programme. The instrument underwent rigorous validation and reliability testing with proven high acceptability and strong criterion validity $(\mathrm{R}=0.58, \mathrm{p}<0.01)$, high internal consistency (Cronbach's alpha 0.856 and 0.890 , respectively $)$, high inter-rater reliability $(\mathrm{R}=0.97$; $\mathrm{p}<0.01)$ and with all floor and ceiling effects less than $15 \%$ (Alkhasawneh et al., 2016).

Statistical analysis was performed using SPSS version 21 (IBM Corp., 2012). Descriptive percentages were used for presenting demographics of the sample. The mean and standard deviation were calculated for general awareness and early detection overall, as well as for each category of the exposure variables.

To account for missing values in the scores for the purposes of correlation and regression analysis, missing score values were imputed using the predictive mean matching method in SPSS. Univariate analysis using Chisquare tests was conducted to test the relationship between demographic variables - education level, income level, age group, marital status and familiarity with a cancer patient - and the general awareness and early detection scores. A backwards multivariate linear regression model was used to estimate the degree and significance (within a $95 \%$ confidence interval) of association between the dependent variables - general awareness score and early detection score - and independent variables found to have significant univariate relationships.

To assess the extent of superstitious beliefs in the sample, the participants' agreement with 'Envy/Evil Eye' as a risk factor was tabulated against the various demographic variables in terms of percentages.

After the quantitative investigation, we investigated further reasons and explanations to the numerical findings through qualitative inquiry. As a mixed methods research, we used a generic qualitative research or interpretive description (Percy et al., 2015). The qualitative strand also provided the study a more in-depth view on the factors that may have enabled or inhibited Omani Women from gaining awareness about breast cancer.

A total of 19 participants were interviewed from the selected governorates of Oman where the quantitative data were collected. Ethical approval was sought and a process consent was gathered from the informants. Using a series of individual interviews, focus group discussions, follow-ups using WhatsApp ${ }^{\mathrm{TM}}$ and mobile technology, the informants shared their insights and thoughts about breast cancer, factors that may affect their awareness and barriers that may hinder early detection. The interviews and discussions were conducted and recorded in Arabic, and were transcribed and translated into English for further synthesis of themes. However, the transcripts were initially synthesized in the local dialect to enhance credibility of the process. Using thematic synthesis, the findings were used to validate the quantitative results, and essential themes were created to provide a comprehensive view regarding the factors which influence awareness of breast cancer among Omani women. Member checking, peer review and consultation of experts (language, medical, cultural) were conducted consistently.

\section{Results}

\section{Demographic results}

Table 1 presents the demographic results. The vast majority of the sample was below the age of 40 years (79.2\%), was married currently or had been at some point of their lives $(79.5 \%)$, and had at least a secondary level of education (86.3\%). Most of the sample had an income below OMR 1000 (\$2600) (60.8\%) per month, while the largest number of households $(36.4 \%)$ were earning between OMR 500 (\$1300) and OMR 1000 (\$2600) per month. 111 participants had a close relative who had been 
diagnosed with breast cancer, while 93 participants knew a friend who had been diagnosed with the disease.

\section{Early detection and general awareness scores descriptive} analysis

The overall mean early detection score was 0.58 $( \pm 0.24)$ and the mean general awareness score was 0.46 $( \pm 0.21)$. Score comparisons for early detection and general awareness for each demographic variable are illustrated in box plots in Figure 1. In terms of age, more participants in the $50+$ age group were less aware than the other age groups. However, there was more variance in the 20-29 age group than any other group.

Participants who had ever been married performed better in both early detection and general awareness. Better education levels showed better scores for general awareness. This trend was also consistent for early

Table 1. Demographic Characteristics of the Sample

\begin{tabular}{lcc}
\hline N=1372 & $\mathrm{n}$ & $\%$ \\
\hline Age Groupa & & \\
$20-29$ & 608 & 44.6 \\
$30-39$ & 472 & 34.6 \\
$40-49$ & 172 & 12.6 \\
$50+$ & 112 & 8.3 \\
Marital Statusb & & \\
$\quad$ Single & 280 & 20.5 \\
Married & 1014 & 74.3 \\
Divorced & 23 & 1.7 \\
Widowed & 47 & 3.4 \\
Education Levelc & & \\
None & 69 & 5.4 \\
Primary & 106 & 8.3 \\
Secondary & 491 & 38.4 \\
Higher & 612 & 47.9 \\
Household Incomed & & \\
$\quad<500$ & 238 & 24.4 \\
500 - 999 & 356 & 36.4 \\
1000 - 1499 & 180 & 18.4 \\
1500 - 1999 & 97 & 9.9 \\
2000 - 2499 & 76 & 7.8 \\
> 2499 & 30 & 3.1 \\
Familiar with Cancer Patiente & & \\
Relative had cancer & 111 & 8.2 \\
Friend had cancer & 93 & 6.9 \\
\hline 8 a & &
\end{tabular}

a 8 missing cases; ${ }^{\text {b }} 8$ missing cases; ${ }^{\text {c }} 94$ missing cases; ${ }^{\text {d }} 395$ missing cases; ${ }^{e} 21$ missing cases; 12 cases with friend and relative with cancer

Table 2. Results of Multivariate Regression between Scores and Demographic Variables

\begin{tabular}{lcc}
\hline Early detection $^{\mathrm{a}}$ & $\mathrm{B}$ & $\mathrm{p}$ \\
\hline Age Group & 0.019 & 0.03 \\
Level of education & 0.024 & 0.01 \\
Marital Status & 0.048 & $<0.001$ \\
\hline General awareness $^{\mathrm{b}}$ & $\mathrm{B}$ & $\mathrm{P}$ \\
\hline Age Group & 0.029 & $<0.001$ \\
Level of education $_{\text {Income level }}$ & 0.031 & $<0.001$ \\
Respondent familiar with cancer patient & 0.014 & 0.01 \\
\hline a Income level and familiarity with cancer patient excluded after univariate &
\end{tabular}

Breast Cancer Awareness and Early Detection Practice in Oman detection. The secondary-educated participants had better scores for early detection, while those with the highest education level had better scores for general awareness.

The median early detection scores for all income levels were generally greater than 0.50 , with the OMR 1000 - 1499 (\$2600-3900) income bracket scoring better than other groups. However, the general awareness scores were better for the OMR 2000 - 2499 (\$5200-6500) income level, and unlike the early detection scores, the general awareness scores showed an increasing trend with increasing income level.

Regression analysis

Table 2 presents the regression analysis.

\section{Early detection}

After univariate analysis, only age, education and marital status were found to have a significant relationship with early detection score, and were included in the multivariate analysis. The magnitude of the coefficients (B) for early detection scores was not very high, but the association was found to be very significant with all three independent variables.
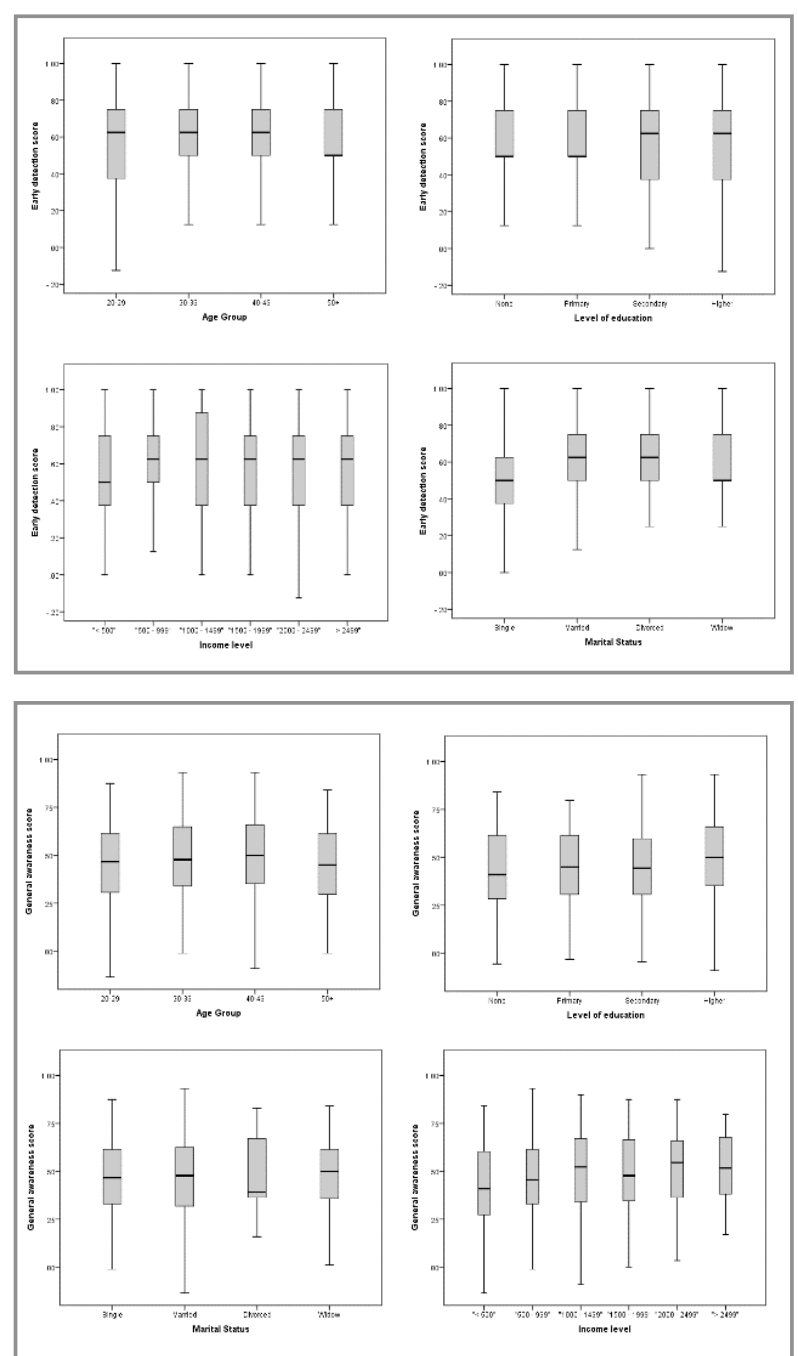

Figure 1. Box Plots Illustrating the Early Detection and General Awareness Scores for Each Demographic Category 


\begin{tabular}{|c|c|c|c|}
\hline Theme & Description of Theme & $\begin{array}{l}\text { Informant / } \\
\text { Data Source }\end{array}$ & Statement Excerpts \\
\hline \multirow[t]{3}{*}{ [I] don't even say "it" } & $\begin{array}{l}\text { The recognition of the Omani } \\
\text { women that breast cancer is a } \\
\text { "taboo", ill-fate, cursed word. }\end{array}$ & $\mathrm{F} 1, \mathrm{I} 9$ & $\begin{array}{l}\text { This is how we feel. Glory for the Lord! Cancer is } \\
\text { associated with death, I mean. When I hear about } \\
\text { cancer, it is death. }\end{array}$ \\
\hline & $\begin{array}{l}\text { Talking about is almost the same } \\
\text { thing with death and should be } \\
\text { avoided to prevent having it. }\end{array}$ & $\mathrm{F} 2, \mathrm{I} 7$ & $\begin{array}{l}\text { Imagine harim (older married women). Anyone } \\
\text { may tell her that she has cancer. She notices this } \\
\text { but she does not want people to talk about it. [She] } \\
\text { does not even want to say that she has cancer. }\end{array}$ \\
\hline & & $\mathrm{F} 1, \mathrm{I} 2$ & $\begin{array}{l}\text { They hide it. They don't like it if someone talks } \\
\text { about it. If someone says that a person has this } \\
\text { disease and that she is sick... she does not like it. }\end{array}$ \\
\hline \multirow[t]{3}{*}{ [I] knew/know "it" } & $\begin{array}{l}\text { Omani women's existing } \\
\text { awareness and need for } \\
\text { knowledge about breast cancer } \\
\text { but still clouded with doubts, } \\
\text { misinformation, superstitious }\end{array}$ & $\mathrm{F} 2, \mathrm{I} 3$ & $\begin{array}{l}\text { I mean most of what we eat these days [are] } \\
\text { canned food we import from abroad. You know } \\
\text { that canned food has preservatives and additives. } \\
\text { We do not realize the harmful effects of such } \\
\text { things which may be a cause of this disease. }\end{array}$ \\
\hline & $\begin{array}{l}\text { beliefs, powerlessness and } \\
\text { inadequacy of information/ } \\
\text { support. }\end{array}$ & $\mathrm{F} 2, \mathrm{I} 2$ & $\begin{array}{l}\text { This is a reminder to us of a topic/case to which } \\
\text { we fail to pay attention yet it is too dangerous. Yet, } \\
\text { it can be treated/curable if discovered early at early } \\
\text { stage. But if discovered late, it will not be easy to } \\
\text { treat or cure so it may be incurable. }\end{array}$ \\
\hline & & $\mathrm{F} 1, \mathrm{I} 6$ & $\begin{array}{l}\text { A while ago there was an education campaign } \\
\text { in the City Center to explain to women how to } \\
\text { conduct the test daily at home by hand (manually) } \\
\text { but I didn't know about it. }\end{array}$ \\
\hline \multirow[t]{3}{*}{ [I] need help for "it" } & $\begin{array}{l}\text { The self-proclaimed urgent } \\
\text { requirement of Omani women for } \\
\text { themselves to be informed and } \\
\text { made aware about breast cancer. }\end{array}$ & $\mathrm{F} 2, \mathrm{I} 7$ & $\begin{array}{l}\text { Our husbands, sons and daughters should be } \\
\text { given even with basic information. They should } \\
\text { be warned and alarmed about the existence of a } \\
\text { disease called breast cancer. }\end{array}$ \\
\hline & $\begin{array}{l}\text { This also pertains to the call for } \\
\text { various key people or institutions } \\
\text { (e.g. husbands, religious leaders, }\end{array}$ & $\mathrm{F} 1, \mathrm{I} 1$ & $\begin{array}{l}\text { It is necessary to have education to increase our } \\
\text { awareness through SMS and others. This will } \\
\text { encourage and promote awareness. }\end{array}$ \\
\hline & $\begin{array}{l}\text { daughters, schools, health settings) } \\
\text { to help women to be empowered } \\
\text { about this health concern. }\end{array}$ & $\mathrm{F} 1, \mathrm{I} 3$ & $\begin{array}{l}\text { This [awareness campaign] is very important [not } \\
\text { just for breast cancer] for those who suffer or even } \\
\text { those who do not. We need it now because many } \\
\text { are suffering from it already. }\end{array}$ \\
\hline \multirow[t]{3}{*}{$\begin{array}{l}{[\mathrm{I}] \text { enable/inhibit to }} \\
\text { become aware of "it" }\end{array}$} & $\begin{array}{l}\text { The acknowledgement of various } \\
\text { factors that may facilitate or even } \\
\text { prevented the women to gain } \\
\text { awareness about breast cancer. } \\
\text { This include enabling/inhibiting } \\
\text { factors of cultural-religion- }\end{array}$ & F1, I6 & $\begin{array}{l}\text { Yes, in the City Center (shopping mall), there } \\
\text { was health education about the different tests on } \\
\text { breast cancer but I was not able to attend the entire } \\
\text { programme. I have not received any SMS, seen an } \\
\text { advertisement or even heard any information about } \\
\text { the programme. }\end{array}$ \\
\hline & $\begin{array}{l}\text { fatalistic system, personal- } \\
\text { familial-environmental system, } \\
\text { and healthcare-political-social } \\
\text { system. }\end{array}$ & $\mathrm{F} 1, \mathrm{I} 5$ & $\begin{array}{l}\text { Doctors themselves may educate the patients } \\
\text { themselves during [women's] regular visit...or } \\
\text { even to my husband who comes with me during } \\
\text { my health center visit. }\end{array}$ \\
\hline & & $\mathrm{F} 2, \mathrm{I} 6$ & $\begin{array}{l}\text { If all will participate in this awareness campaign } \\
\text { - our families, schools, mosques, and our older } \\
\text { people - this will be a very effective health } \\
\text { strategy. Also, make this accessible to everyone - } \\
\text { especially in the villages - and implement different } \\
\text { information dissemination techniques such as } \\
\text { WhatsApp, SMS, TV advertisement, posters, } \\
\text { mobile applications and others. }\end{array}$ \\
\hline
\end{tabular}

* F- Focus Group Discussion; I - Informant

\section{General awareness}

Marital status did not demonstrate any significant univariate relationship with general awareness, and was excluded from the multivariate analysis. For the general awareness scores, the regression coefficients were similarly low, but the association was statistically significant with income level, education level, age group and familiarity with cancer patient.

\section{Superstitious beliefs descriptive analysis}

As shown in Figure 2, a majority of the sample (59.5\%) believed that envy or evil eye was a risk factor for breast cancer. This belief was most prevalent among the youngest age group, which also reflects the large number of the sample who belong to this age group. However, the largest 


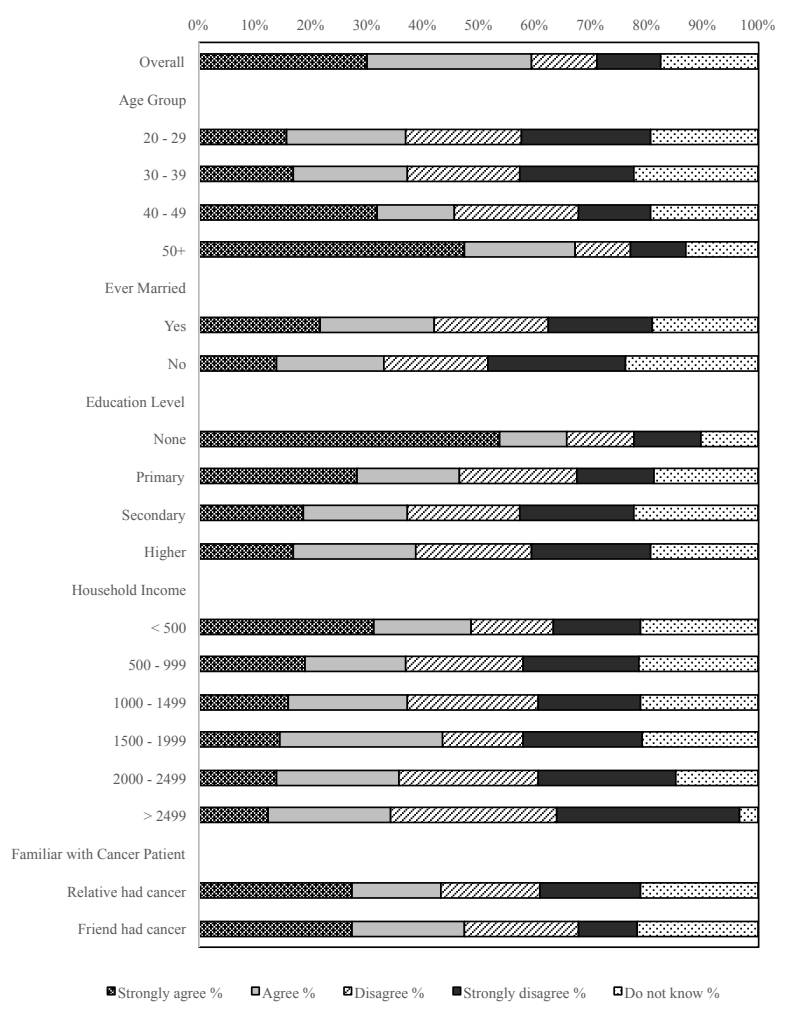

Figure 2. Belief in Evil Eye/Envy As Risk Factor for Breast Cancer, According to All Demographic Categories



Figure 3. Model of Enabling Systems with Increasing Modifiability with Increasing Distance from the Omani Woman

proportion which disagreed with this belief was also found in this age group.

The belief was more prevalent among those who had ever been married than those who had never been married; however, the majority among both categories of women believed in evil eye as a risk factor for breast cancer. The majority of participants from all education backgrounds tended to agree with this belief, but the proportion of the majority was highest for those with no education (80.6\%). While the same beliefs existed for the majority among all income levels, the distribution across the degree of beliefs in the Likert scale was spread out for those in the highest income level. A large majority $(63.1 \%)$ of those who knew a friend or relative diagnosed with breast cancer agreed with the belief in this risk factor.

\section{Significant themes}

The qualitative findings provided the research a more
Breast Cancer Awareness and Early Detection Practice in Oman

comprehensive view on the awareness of Omani women on breast cancer. It is important to emphasize that the demographic and cultural background of the women affected their insights towards this particular type of cancer. Based from their sharing of thoughts and outlook about their awareness - breast cancer in general and actions to detect or even cure it - significant, recurrent and unifying themes were developed as presented below. The themes are presented similarly by starting with the word I but in an enclosure [ ] or square brackets/parenthesis. In mathematical sense, brackets are indicative of analysing expressions inside it first than any other. The same is true with the Omani women, in relevance with the breast cancer, for they should (as they also firmly believe) be empowered first and foremost, to gain control, take action and live with an investing attitude towards health and self. In the contrary, in English and language context, using a bracket or parenthesis for a word in a sentence indicates a missing term or implies that the meaning and flow of the text is supplemental to the rest of the text. But with the presented themes, the whole thought would be changed were the parenthesized word 'I' when removed will mean a more active, commanding/requesting rather than being informative and self-directing. (e.g. [I] don't even say 'it' will be modified to don't even say 'it'). Further, each statement theme had a very distinct 'it' to emphasize how 'taboo' breast cancer in the Omani society is. 'It' connotes that breast cancer is way to represent how people avoid the said word. Further explanations are discussed with the theme pertaining to it. The themes are presented in Table 3 with the description and a sample narrative from the informant.

The discussions and interviews presented similar and overarching themes encompassing different enabling systems that Omani women believe enable or inhibit them in increasing awareness. We grouped the systems as the cultural-religious-fatalistic system, the personal-familialenvironmental system, and the healthcare-related system, listed here in increasing levels of modifiability. The enabling/inhibiting systems and the contexts presented by the Omani women were used to develop a model of enabling systems (Figure 3) to illustrate the dynamics between these systems, as well as highlight the influence of the external enabling systems on each other - particularly to Omani women through the "pouring-in process".

As the women shared their minimal yet necessary knowledge about breast cancer and provided different strategies to employ the systems to help Omani women gain more awareness and knowledge on breast cancer, the model incorporated the "out-pouring process". This process involves the encouragement of Omani women to initiate interventions starting from self-empowerment, moving from the most rigid system outwards.

\section{Discussion}

Our quantitative findings demonstrate a general trend of better awareness with age, income level, education level and familiarity with a cancer patient, when each of these independent variables is adjusted for others. Such a trend also exists for early detection behaviour with age, marriage and increasing education. 
Similar results in the Arab region - including one which used a translated version of the BCAM - reported inadequate knowledge of breast cancer and screening (Al-Khasawneh, 2007; Habib et al., 2010; Radi, 2013; Renganathan et al., 2014). Only half the surveyed women were able to identify a lump in the breast as a possible warning sign in Jeddah, Saudi Arabia (Radi, 2013).

The results showed a positive and significant relationship between age and both, early detection and general awareness. While better general awareness scores for older women could be a result of accumulated health knowledge, younger women might score less on early detection since they might not be as concerned about breast cancer as older women.

In our study, the positive association of general awareness with income was statistically significant, even when adjusted for education, age, marital status and familiarity with cancer patients. However, the univariate analysis between early detection and income level did not demonstrate a significant relationship. This suggests the possibility that while general awareness increased with income level, this knowledge was not necessarily applied in early detection practices.

Early detection and general awareness had a similar relationship with participants' familiarity with a cancer patient, positing the idea that while general awareness is better with familiarity, the knowledge is not being employed in early detection. Earlier studies have suggested that witnessing a relative dying from breast cancer may increase beliefs of futility in early detection (Azaiza and Cohen, 2006; Azaiza et al., 2010), and our conjecture is that the lack of a relationship with early detection could be illustrative of such a phenomenon. However, the small number of participants who had familiarity with cancer patients prevents us from being conclusive about this finding.

With marital status, while there was a significant relationship with early detection when adjusted for other demographic variables, there was no significant univariate relationship with general awareness. When looking at the descriptive analysis trend, we speculated that evermarried women being slightly older might also have the benefit of more accumulated overall knowledge. We tested this speculation by estimating the correlation between having ever been married and age, and found a significant correlation $(\mathrm{R}=0.373, \mathrm{p}<0.001)$. However, in our opinion, the discrepancy between early detection and general awareness scores with marital status could be a cultural artefact. We were able to ascertain that the correlation between education and ever being married is negative and significant $(\mathrm{R}=-0.209, \mathrm{p}<0.001)$ - suggesting that single participants tended to have better education and better knowledge of breast cancer. This could be due to younger women going further in education before marriage, since we found a negative significant correlation between education and age $(\mathrm{R}=-0.566, \mathrm{p}<0.001)$. However, to explain the significant association between marital status and early detection, one of our conjectures is that single women could be more sheltered from taboo issues - as we ascertained from qualitative data - and married women are able to practice early detection behaviour without worrying about societal pressures. We also posit that this may have to do with more access to primary healthcare, as well as medical counselling after marriage.

However, we urge further exploration of these regression analysis hypotheses before concluding any facts about the nature of relationship of early detection and general awareness scores with demographic variables.

The qualitative findings intensified the quantitative findings by providing factors that may have affected their awareness at different levels. Omani women strongly advocate programmes to increase the awareness of the entire society (not just women), encourage social involvement and participation, debunk health taboos and initiate social action and movement. Resilient emphasis is placed on the role of the husbands and men in general, religious leaders and health personnel or even political leaders. Various strategies were also suggested with greater inclination in the use of technology and publicity materials. Incorporating all the efforts into the system and society plays an important and essential role in increasing women's awareness. It was noted that there are three main systems that can either facilitate or even inhibit the achievement of awareness among Omani women. This includes cultural-religion-fatalistic system, personal-familial-environmental system, and healthcarepolitical-social system. The themes from the discussions and interviews demonstrated that these systems have an increasing level of rigidity to change the closer they are to Omani women. Thus, the model serves an important purpose in the development of awareness interventions: utilising existing systems to enable Omani women in a "pouring-in" process, and then utilising empowered Omani women to modify systems from the innermost culturalreligion-fatalistic system outwards in an "out-pouring" process has the potential for a sustainable awareness and behavioural change intervention. Further study is required in order to validate the claims of this model.

Both the quantitative and qualitative results indicated the deeply ingrained belief in superstition across all demographics of Omani society. The level of education or socioeconomic status had no bearing on whether participants believed in the role of 'evil eye' in causing breast cancer, since an overwhelming majority in almost all categories of all demographic exposures believed this to be true. Any health promotion interventions which deal with breast cancer in Omani society will need to account for this belief to address the taboo and myths that are associated with the disease, and in so doing they would ensure better access to screening and treatment through rational decision-making (Al-Azri et al., 2014).

Any future studies will greatly benefit from including a fatalistic beliefs scale to the survey instrument, since fatalistic beliefs in morbidity and mortality as unalterable divine will have been found to be prevalent in Arab populations (Matin and LeBaron, 2004; Cohen, 2013; Kawar, 2013; Mellon et al., 2013). Scoring on this scale would allow public health authorities in the country to incorporate the awareness that the disease is likely to be treated and possibly cured if detected in a timely manner (Padela et al., 2015), since fatalism forms part of the most rigid system in the enabling systems model. 
Several studies have found that culturally-sensitive breast cancer education programmes can have a significant impact on changing knowledge and beliefs about breast cancer (Hall et al., 2005; Bickell et al., 2009). Researchers have recently been focusing on the possibility that culturally-tailored behavioural change programmes may affect cancer screening practices to better eliminate known barriers and provide appropriate interventions (Simon, 2006; Donnelly and Hwang, 2015). Little is known about the perceptions, attitudes, barriers and facilitators related to breast cancer prevention perceived by Omani women. Such understanding is an important step to identify the areas where women need to be educated and to develop culturally-tailored programmes and activities, and to define best strategies to apply available resources, which would lead to identifying breast cancer at a $\mathrm{n}$ earlier stage to improve breast cancer outcome and survival. Alkhasawneh E, Leocadio M, Seshan V, et al (2016). Transcultural adaptation of the Breast Cancer Awareness Measure. Int Nurs Rev, (In Press).

\section{Study Limitations}

The current study was limited by the cross-sectional study design. The sample recruitment was not randomised, even if the locations for recruitment were chosen at random. We were compelled to use convenience sampling after our experience with sampling for instrument validation (Alkhasawneh et al., 2016). The randomised recruitment during instrument validation had a high refusal rate: women refused to participate since they believed that association with the survey would put them at risk of contracting the disease, demonstrating another aspect of superstition in health behaviour. Others refused because they did not deem themselves capable of 'answering correctly'. Even though a convenience sampling method was used, the sample managed to reflect the age demographics of the Omani population to a large extent (Ministry of National Economy, 2010).

The results demonstrate that further research is required urgently, and future qualitative studies on Omani women's beliefs and perceptions about the various aspects of breast cancer would also benefit from juxtaposing the beliefs of expatriate women of different backgrounds residing in Oman with those of Omani women. While adding dimensions to the current understanding of how breast cancer is perceived in Oman, the results of such studies will lend nuance to breast cancer-related health promotion campaigns in the country.

In conclusion, breast cancer remains a taboo topic in most Arab countries. Most people still refer to it as 'that other disease' and remain afraid of mentioning it by name (Azaiza and Cohen, 2006). Specific actions are needed to favour equitable access to breast screening for all women in Oman. Thus, a thorough understanding is needed of the perceptions, attitudes, barriers and facilitators in regard to breast cancer prevention perceived by Omani women. Collecting data on breast cancer is imperative for deciding how best to apply resources.

Culturally-tailored breast awareness intervention can contribute in disseminating more knowledge, and reducing the stigma around breast cancer through
Breast Cancer Awareness and Early Detection Practice in Oman

education on symptoms, early screening and treatment and promoting systematic and programmed early detection. Furthermore, treatment of early-stage breast cancer is typically simpler and more cost effective than treatment of advanced disease. However, these efforts should only be implemented in a holistic, comprehensive manner using various strategies appealing to Omani women to ensure effectiveness and efficiency.

\section{Acknowledgements}

The authors are grateful for the support from His Majesty's Research Fund.

\section{References}

Al-Azri M, Al-Awisi H, Al-Rasbi S, et al (2014). Psychosocial impact of breast cancer diagnosis among Omani women. Oman Med J, 29, 437-44.

Alkhasawneh E, Leocadio M, Seshan V, et al (2016). Transcultural adaptation of the Breast Cancer Awareness Measure. Int Nurs Rev, (In Press)

Al-Khasawneh E (2007). Knowledge and practice of breast cancer screening among Jordanian women. Oncol Nurs Forum, 34, 1211-7

Al-Moundhri M, Al-Bahrani B, Pervez I, et al (2004). The outcome of treatment of breast cancer in a developing country - Oman. Breast, 13, 139-45.

Anderson B, Jakesz R (2008). Breast Cancer Issues in Developing Countries: An Overview of the Breast Health Global Initiative. World J Surg, 32, 2578-85.

Azaiza F, Cohen M (2006). Health beliefs and rates of breast cancer screening among Arab Women. J Womens Heal, 15, 520-30.

Azaiza F, Cohen M,Awad M, Daoud F (2010). Factors associated with low screening for breast cancer in the Palestinian Authority: relations of availability, environmental barriers, and cancer-related fatalism. Cancer, 116, 4646-55.

Bickell N, Weidmann J, Fei K, Lin J, Leventhal H (2009). Underuse of breast cancer adjuvant treatment: patient knowledge, beliefs, and medical mistrust. J Clin Oncol, 27, 5160-7.

Simon C (2006). Breast cancer screening: cultural beliefs and diverse populations. Health Soc Work, 31, 36-43.

Hall C, Wimberley P, Hall J, et al (2005). Teaching breast cancer screening to African American women in the Arkansas Mississippi river delta. Oncol Nurs Forum, 32, 857-63.

Cancer Research UK (2008). Cancer Awareness Measure (CAM) Toolkit (version 2.1) [PDF Document]. Cancer Research UK.

Cohen M (2013). An integrated view of cultural perceptions of cancer among Arab people in Israel. Health Psychol Rev, $\mathbf{8}, 490-508$.

Donnelly T, Al Khater A, Al-Bader S, et al (2013). Beliefs and attitudes about breast cancer and screening practices among Arab women living in Qatar: a cross-sectional study. $B M C$ Womens Health, 13.

Donnelly T, Hwang J (2015). Breast cancer screening interventions for Arabic women: a literature review. J Immigr Minor Health, 17, 925-39.

Habib F, Salman S, Safwat M, Shalaby S (2010). Awareness and knowledge of breast cancer among university students in Al Madina Al Munawara region. Middle East J Cancer, 1, 159-66.

International Agency for Research on Cancer (IARC) (2012). GLOBOCAN 2012: estimated cancer incidence, mortality and prevalence worldwide in 2012. international agency for 
Esra M Al Khasawneh et al

research on cancer

IBM Corp (2012). IBM SPSS Statistics Version 21 .0. IBM Corp.

Kalager M, Zelen M, Langmark F, Adami H (2010). Effect of Screening Mammography on Breast-Cancer Mortality in Norway. N Engl J Med, 363, 1203-10.

Kawar L (2013). Barriers to breast cancer screening participation among jordanian and palestinian American women. Eur $J$ Oncol Nurs, 17, 88-94.

Kumar S, Burney I, Al-Ajmi A, Al-Moundhri M (2011). Changing trends of breast cancer survival in sultanate of oman. J Oncol, 2011.

Linsell L, Forbes L, Burgess C, et al (2010). Validation of a measurement tool to assess awareness of breast cancer. Eur J Cancer, 46, 1374-81.

Matin M, LeBaron S (2004). Attitudes toward cervical cancer screening among muslim women: a pilot study. Women Health, 39, 63-77.

Mellon S, Gauthier J, Cichon M, Hammad A, Simon M (2013). Knowledge, attitudes, and beliefs of Arab-American women regarding inherited cancer risk. J Genet Couns, 22, 268-276.

Ministry of National Economy (2010). Oman census 2010 Results [PDF Document]. ministry of national economy.

Padela A, Murrar S, Adviento B, et al (2015). Associations between religion-related factors and breast cancer screening among American muslims. J Immigr Minor Heal, 17, 660-9.

Percy W, Kostere K, Kostere S (2015). Generic qualitative research in psychology. Qual Rep, 20, 76-85.

Radi S (2013). Breast cancer awareness among Saudi females in Jeddah. Asian Pac J Cancer Prev, 14, 4307-12.

Raza S, Sajun S, Selhorst C (2012). Breast cancer in Pakistan: identifying local beliefs and knowledge. J Am Coll Radiol, 9, 571-7.

Renganathan L, Ramasubramaniam S, Al-Touby S, et al (2014). What do omani women know about breast cancer symptoms? Oman Med J, 29, 408-413.

Underwood S, Shaikha L, Bakr D (1999). Veiled yet vulnerable: breast cancer screening and the Muslim way of life. Cancer Pract, 7, 285-290.

Welch $\mathrm{H}$ (2010). Screening mammography-a long run for a short slide? N Engl J Med, 363, 1276-8.

World Health Organization (2014). WHO I Breast cancer: prevention and control. WHO. 